\title{
Article
}

\section{"Opinion and Fact, Perspective and Truth": Seeking Truthfulness and Integrity in Coaching and Coach Education}

Stoszkowski, John Robert, Macnamara, Aine, Collins, David John and Hodgkinson, Aran

Available at http://clok.uclan.ac.uk/33851/

Stoszkowski, John Robert ORCID: 0000-0002-1968-5770, Macnamara, Aine ORCID: 0000-0002-8110-6784, Collins, David John ORCID: 0000-0002-76010454 and Hodgkinson, Aran ORCID: 0000-0002-2310-5804 (2020) "Opinion and Fact, Perspective and Truth": Seeking Truthfulness and Integrity in Coaching and Coach Education. International Sport Coaching Journal . ISSN 2328-918X

It is advisable to refer to the publisher's version if you intend to cite from the work. http://dx.doi.org/10.1123/iscj.2020-0023

For more information about UCLan's research in this area go to http://www.uclan.ac.uk/researchgroups/ and search for <name of research Group>.

For information about Research generally at UCLan please go to http://www.uclan.ac.uk/research/

All outputs in CLoK are protected by Intellectual Property Rights law, including Copyright law. Copyright, IPR and Moral Rights for the works on this site are retained by the individual authors and/or other copyright owners. Terms and conditions for use of this material are defined in the policies page. 
"Opinion and Fact, Perspective and Truth": Seeking Truthfulness and Integrity in Coaching and Coach Education

4

5 John Stoszkowski ${ }^{a *}$, Áine MacNamara ${ }^{\mathrm{b}, \mathrm{c}}$, Dave Collins ${ }^{\mathrm{c}, \mathrm{d}}$ and Aran Hodgkinson ${ }^{\mathrm{a}}$

6

$7 \quad{ }^{a}$ School of Sport and Health Sciences, University of Central Lancashire, Preston, UK.

$8 \quad{ }^{b}$ School of Health and Human Performance, Dublin City University, Dublin, Ireland.

$9 \quad{ }^{c}$ Grey Matters Performance Ltd. Stratford upon Avon, England

${ }^{d}$ Moray House School of Education and Sport, University of Edinburgh, Scotland

*Corresponding author. School of Sport and Wellbeing, The University of Central Lancashire,

Preston, UK, PR1 2HE, Tel 01772895702.

Email: JRStoszkowski@uclan.ac.uk

Date of first submission: $7^{\text {th }}$ March 2020

17

Date of revised submission: $16^{\text {th }}$ April 2020

Date of second revision: 23rd June 2020 
Recent developments have seen a growth in coaching, with an associated boom in interest on how it may be optimised. Clearly, we applaud this evolution. This growth has been paralleled by an explosion in the availability of information, driven through internet access and the phenomenon of social media. Unfortunately, however, this juxtaposition of interest and availability has not been matched by the application or exercise of effective quality control! While much of what is available is well intentioned, a tendency for poor quality and possibly less positively targeted "BS" has also arisen. In this insights paper, we consider some of the reasons why and argue that an emphasis on the development of critical and analytical thinking, as well as a scepticism towards the sources of information, would be a positive step against coach susceptibility to BS. In doing so, and to encourage more critical consumption of the "knowledge" available, we present a checklist to help coaches assess the veracity of claims and sift through the noise of the coaching landscape. 
“Opinion and Fact, Perspective and Truth": Seeking Truthfulness and Integrity in Coaching and Coach Education

Coaching and (hopefully therefore) coach education is a growing business. Internationally, as people recognise the importance of interpersonal interactions as facilitators of much needed physical activity and socially positive interaction, governments and organisations are becoming increasingly aware of the need for a well-educated, well informed and appropriately professional coaching workforce (Trudel, Milestetd, \& Culver, 2019). In the UK, as an example of other national initiatives, organisations such as UK Coaching (www.ukcoaching.org) or the International Council for Coaching Excellence (www.icce.ws) are working hard to establish themselves as the gatekeepers of knowledge distribution and accreditation. The profession is in an apparent boom.

As this trend gathers pace, however, we may also be facing a "crisis of information" in this crucial field. Our title is taken from the famous orator, writer and doubtless coach educator Marcus Aurelius, who is often quoted as saying "Everything we hear is an opinion, not a fact. Everything we see is a perspective, not the truth." Except he didn't, or there is no credible citation of him having said it at least (Sylvester, 2019). We use this to stress the essential need for criticality in knowledge consumption and application for coaches, matched by overt and transparent qualification as to the limitations inherent in the stances presented by educators. Unfortunately, as we also hope to demonstrate, both criticality and qualification are depressingly rare, even worse an occurrence in the face of a rising tide of bullshit (hereafter BS) which, we would contend, is playing a worryingly growing role in filling the knowledge gap in coaching.

Reflecting this worrying juxtaposition (increasing BS against an increasing hunger for knowledge) we present this paper as a stimulus for critical consideration and debate. Firstly, we examine the phenomenon of BS, addressing its underpinnings, some distinctions between 
this and its older, if often rather close relation of lying, and why it might be of increasing concern. We then situate this concerning behaviour within coach education and learning, offering an opinion on what, why and how this might do to the essential development process. We then offer some ideas for how to address this trend; namely, the development of critical skills as a common and socially encouraged (cf. Stoszkowski \& Collins, 2014) feature of the coaching environment. We conclude with a call for action and debate; after all, the more we talk about this the less likely it is to promulgate!

\section{Bullshit}

BS, defined by Frankfurt (2005) as the process of communicating with little to no concern for evidence or truth, is all around us. It might even be said that "BSing" (the verb of BS!) is now the norm (Christensen, Karreman, \& Rasche, 2019), with even those in the highest echelons of political power openly employing obscure, empty or pretentious talk (Kelly, 2014) to evade responsibility and/or justify their decision making. Building on Frankfurt's seminal work, Petrocelli (2018, p. 249) further defines BS as “communications that result from little to no concern for truth, evidence and/or established semantic, logical, systemic, or empirical knowledge." BSing is generally said to occur because people feel they must hold or express an opinion that makes them appear informed on almost everything (Frankfurt, 2005). In these situations, when people do not have the information or evidence required to converse about a given topic, they often simply create an illusion that they do by BSing. People naturally want to be perceived as knowledgeable, well informed and intelligent (cf. Tetlock \& Gardner, 2015) and, if they do not possess knowledge that is underpinned by theoretical or logical evidence, they often try to disguise the fact that they lack this knowledge by delivering information with disregard for its truthfulness or inherent limitation. We recognise the difficulties of defining "truth" (Williams, 2002) with its connected set of notions such as belief, reference and meanings. However, in the context of this paper, we 
emphasise the importance of being "truthful" and echo MacKenzie and Bhatt's (2020a) suggestion that truthfulness entails qualities such as sincerity, accuracy, trust, trustworthiness and truthfulness.

It is important to note, however, that a BSer is not exactly the same as a liar. A liar's objective is to intentionally deceive those that they are lying to, and the liar has an understanding or knowledge of the truth, yet they lie in order to obscure the truth from others (MacKenzie \& Bhatt, 2020b). For example, a college coach might knowingly lie to a recruit about the playing time he or she will receive during their first year on the team. This offers a good illustration of our point about truthfulness. In this context, the coach is well aware of the factual truths (or at least what s/he believes them to be) but still makes the statement! In contrast to the liar, however, who often has some regard for or knowledge of the truth and consciously attempts to subvert it (Cole, 2001), the BSer has no concern for such actions. Although the liar and the BSer both pretend to tell the truth, the BSer may have no intention of being cunning or deceitful (like the liar) but instead, simply relinquishes any responsibility for communicating the truth. For example, a presenter at a coaching conference is asked a question about a new training method that s/he does not know much about, but to maintain their image as an "expert" they provide an answer. Or a prominent blogger, who does not really understand the nuances of different skill acquisition approaches, continues to dismiss one method as it disagrees with what his/her blog or website is promoting. Notice, however, that in both of these examples the line between lying and BS can be rather blurred, or at least hard to discern. The intention of truthfulness is the key distinguishing factor, but one usually has to investigate the perpetrator carefully to accurately ascertain this.

Other BS characteristics can also be seen, although they may still be hard to label accurately. The BSer is often less analytical and deliberate; indeed, s/he often rather enjoys the freedom of transferring the knowledge "possessed" to people while insufficiently 
regarding truth or facts (cf. Lindskold \& Walters, 1983). Unfortunately, it appears that people are often extremely willing to offer judgments and opinions about subjects they know too little, if anything, about in order to appear knowledgeable (Herr, Sherman, \& Fazio, 1983). Furthermore, and perhaps worryingly, people who often BS may eventually believe their own BS. In fact, cognitive dissonance may lead to motivated forgetting of information that does not align with the BS and may lead to inflated belief and confidence in the false information (Polage, 2017). As a consequence, and despite a lack of evidence to support their opinion, the BSer can often consider what they say to be true (Luks, 2017). We leave it to the reader to characterise such behaviour on the BS-liar spectrum!

BSing is said to be increasingly prevalent because, at least in part, people feel obliged to engage with others on matters that they are not well educated on but feel strongly about (Frankfurt, 2005). People feel inadequate, uninformed and uneducated if they cannot effectively express a view on a significant number of subjects; consequently, BSing takes place. Moreover, BSing has increasingly become a societally detrimental but personally rewarding hobby and social activity (Pennycook \& Rand, 2019; Spicer, 2013), where people lack concern or consideration for evidence or established knowledge. As a result, BS permeates the information we are bombarded with on a daily basis (Crockett, Dhar, \& Mayyasi, 2014), particularly through that increasingly popular source of information, social media. In this paper, we argue that much current and popular discourse in coaching is impacted by BS (both actual and unintentional) and equipping coaches with the required tools and strategies to discern and detect BS is therefore an important coaching intervention.

\section{BS in Coach Learning and Development}

In recent years, online technology and social media platforms have become extremely sophisticated tools that now dominate the way we communicate and share information in our everyday lives (Pennycook \& Rand, 2019). Popular platforms like Twitter, Instagram and 
146 Facebook operate based on user generated content, online collaboration, information sharing, 147 and collective intelligence (Akram \& Kumar, 2017). Given that most smartphones also support access to these platforms, people are provided with 24/7 interactivity and content on demand. As a consequence, social media permeates our lives at home, in the workplace and within our education system (Nielsen, 2015). Indeed, many educational institutions and organisations now utilise web-based apps and social networking tools as a mechanism to improve student engagement and attainment (Baran, 2010; Dabbagh \& Kitsantas, 2012; Jamro \& Shaikh, 2016).

It is well documented that sports coaches prefer informal methods of learning as opposed to formal, tutor-led coach education courses (Stoszkowski \& Collins, 2016; Walker, Thomas, \& Driska, 2018). Consequently, online tools that allow coaches to interact, collaborate and co-construct knowledge have been viewed as ripe for exploitation in coach education (Piggott, 2013) and they have seen dynamic growth as both a compliment and alternative to traditional face-to-face formal courses and certifications. For example, the UK's largest national governing body (NGB), the Football Association, provides its coaching community with free access to Hive learning (https://www.hivelearning.com), an online collaborative learning platform that allows groups of coaches to share and discuss resources and session ideas. Similarly, the charity UK Coaching (an umbrella body for coaching), administers and moderates Connected Coaches (https://www.connectedcoaches.org/), a free to access online community that allows coaches to access resources, swap ideas and share knowledge; or what might be more accurately described as their experiences and perceptions.

167 Even more informally, however, coaches increasingly use online platforms such as Twitter, Facebook, podcasts and blogs to share ideas and acquire information (Stoszkowski \& Collins, 2016). 

increase in the prevalence of independent/private providers of coach education and development opportunities. These providers range from lone individuals and sole traders to comparatively larger commercial enterprises who, in the UK at least, offer a varied menu of activities including mentoring, workshops and conferences, often at significant expense to attendee coaches. These "products" are often offered directly to coaches, outside of any "formal" programme of study, as well as through NGBs as part of the educational diet they promote to their coaches. Notably, it appears, on the face of it at least, that many of these providers first build up a following on the aforementioned social media channels, before closing in on some elements of content then marketing the specific products, resources or programmes that they offer to this following. Confusingly, the lines of independence are often blurred too, with former (and current!) NGB/NSO staff and associates often being involved in both promoting and delivering these activities in parallel to other more formal duties. Indeed, the promotion and delivery of these activities reflects tenets of BS highlighted elsewhere in the literature (Pennycook, Cheyne, Barr, Koehler, \& Fugelsang, 2015) in that they strive to impress rather than inform and be engaging rather than informative (Bailey, Madigan, Cope, \& Nicholls, 2018). For example, private/commercial providers of coach education may insist on using "impressive sounding claims and language" (Pennycook et al., 2015 , p.549) to get bums on seats, or jargon, which is intentionally unclear and/or confusing to the audience.

It would be "inappropriate" to offer explicit examples of BS. Indeed, without a careful and well-argued counter case to the example, we may well be guilty of BS ourselves! Reflecting our comments earlier, intention must play a part in discerning BS and, in the absence of insider knowledge, one must apply the benefit of the doubt. It is, however, pertinent to offer examples which readers may recognise of situations which often result in 
BS-like positions. For example, taking a particular position (e.g., anti-the use of drills) then promulgating lots of drill-like ideas; a common feature at the time of writing as the Covid-19 lockdown impacts on the social media environment. Another situation is a podcast inviting on a guest speaker (often a high-quality researcher) then "twisting" their stance to support your new product. As a final example, we would highlight the dual-role status of many commercial website owners. Holding a role with an NGB/NSO while also selling materials through subscription services or conferences which trade on the dual status. Of course, returning to our points earlier, this may be fine. After all, we are unaware of these individuals' job descriptions! There would appear to be at least a hint of a clash of interests, however, especially when one presents material commercially through one setup that is also your responsibility to promote when wearing the hat from your other setup!

Given how the growth and expansion of internet access, social media and technological advances has fundamentally changed the way coaches work and learn, as well as an educational diet that increasingly includes exposure to these commercial providers of "content," it is clear that coaches are increasingly operating in an educational milieu that likely provides an abundance of opportunity to both share and be exposed to BS (Stoszkowski \& Collins, 2016). Furthermore, this BS is far more likely to spread when those who are exposed to it are simply not able to detect, challenge, question, or refute it (Pennycook et al., 2015). All too often, when individuals encounter new information, they fail to identify that it may require deeper consideration in order to judge its truthfulness. Of course, it is efficient and necessary to believe something because of the claims of others; without this our knowledge would be limited to a tiny dataset of personal experience. However, failure to apply appropriate analytical reasoning processes (Pennycook, Fugelsang, \& Koehler, 2015) and instead, take information at face value and without sufficient scepticism, likely leads to BS being accepted by one person and then shared with another. For 
example, the spread of ideas through the social network of coaching is well documented (cf. Stoszkowski \& Collins, 2014). Unfortunately, the power of this social spread may well carry more "clout" than the receiver's own critical appraisal. In short, many may succumb to the quality of marketing as opposed to the veracity of the argument. Our earlier example of recruiting an authority to speak on your podcast then misrepresenting their ideas (as either lying or BS) is one example of this social contagion marketing (Barash, 2012). There is a clear need, therefore, to consider what kind of impact this social selling effect may have on the efficacy of coach learning, and what we might need to do to mitigate the potential negative impacts of it.

\section{Critical Thinking: Coaches as Critical Consumers of Information}

As highlighted above, we live in an information rich world and it has never been easier to access content whether through coaching resources, academic sources, search engines, or social media. The latter is an undoubtedly powerful and impactful tool and, when used properly, can be an important method of information-sharing and collaboration.

However, the extent to which the information is evidence-based rather than opinion-based, or even whether this distinction is acknowledged, is at best questionable, especially given the means by which ideas on social media platforms gain traction. As such, it is important that coaches exercise caution in what they believe and, in the absence of verifying evidence, it is critical to be careful about the veracity of the claims made. Of course, we are also not saying that academics should be the only gatekeepers of knowledge; indeed, as we stress later the proliferation of these data sources may be laid, in part, at the feet of academic waffle, selffocused onanism and/or poor science (cf. Collins \& Bailey, 2013). It may well be, at least in part, that social media sources have merely grown to fill the void! It must surely be acknowledged, however, that for all its faults (cf. Smith, 2006) the peer-review process does provide a level of rigour that is lacking in a "free for all" online world (Wingfield, 2017). 
information consumed and subsequently used by coaches is, of course, crucial. In an ideal world, information should only be disseminated with quality assurance. Online, however, the quality of the information and, equally importantly, the balance of the information circulated, does not undergo any quality control. What are the consequences of this unfiltered data? Firstly, the coach can choose what and who to listen to. The assumption is that people listen to people who hold similar views to themselves; we follow people on Twitter, for example, who share "tweets" about things that appeal to us (Akram \& Kumar, 2017). This selfselection builds up a shared community of individuals with similar opinions and, by virtue of preferential attachment (Matthews, 2016), information gains credibility and traction in a "rich get richer" fashion. For example, those with the most followers are most likely to have their ideas heard and subsequently shared which, in turn, will lead to more followers. In much the same manner, those with few followers are unlikely to have their ideas amplified, and people with opposing opinions can be unfollowed (or even blocked!) so those tweets, and contrary opinions, do not appear on your Twitter feed. By doing this, the coach does not have to contend with conflicting evidence or people questioning his/her stance. Furthermore, this merely magnifies the social contagion selling we mentioned earlier; this must be right because everyone (that you are listening to) says so! Social media is founded on connections and relationships that promote information sharing (Matthews, 2015) but this feature has significant potential for negative impact when this is done in a self-selected manner. Indeed, the ability to circulate ideas that are persistent and persuasive but potentially without evidence is a real danger. As such, there is an important distinction to be made between the need to acknowledge experiential knowledge (cf. Martens, 1987) and the more causal "in my experience" opinion, however well qualified the source. The former is usually part of a careful process of execution, critical reflection and 
refinement (Eyler \& Giles, 1999). The latter can often represent a throw away comment made when someone is asked for their opinion on a topic, which may often not have been directly experienced!

Of course, in epistemology testimony is an important consideration in terms of consideration whether a belief is true and when a belief counts as knowledge. For example, if I trust the source, then I take the information and use it to inform my own practice. However, employing this form of indirect knowledge is only useful when you believe things that are actually true. As such, an important truth-seeking skill is learning how to assign trust. The current social media environment has seen the rise of the "guru" who, often without qualification or with a rather selective presentation of some choice titbits of information, present an answer as "the" answer (Sperber, 2010). As we stress in our conclusion, knowledge is surely contextual, and solutions would therefore be best seen as optimum to a particular context. Failing to recognise this conditionality smells of BS. Furthermore, we should surely recognise and acknowledge the quality of our experiences in offering an opinion. To clarify our point in the previous paragraph, I might express my opinion on rugby coaching as an experienced, deep thinking and highly reflective coach. I might also offer some opinion on coaching football prefaced by "in my experience," but are my two comments of different value or veracity? And should I not explain the distinction? The bottom line is that such communications must come with, at the very least, a health warning or preferentially, a balancing argument. Those in positions of authority, indeed those with a sense of social responsibility, whether they be academics, coaches, NGBs, or commercial agencies, surely have a responsibility to ensure there is an evidence basis and conditionality (i.e., when it applies but also when it might not, coupled with the experience base for my opinion) to the information they share. Furthermore, that private agendas are not pushed or, if mentioned, qualified through context. This is especially 
important when the consumers of this knowledge (e.g., coaches) may be swayed by the authority (e.g., professional standing, associated appointment, accreditation, certification or social media following) of those sharing information, concentration of persuasive, (apparently) face valid but evidence lacking "tweets," or the skills to filter the good from the bad.

Secondly, with an abundance of available information, how do coaches sift out the misinformation and bogus claims, and get to the truth? The issue is not that everything available online, or indeed through other sources (coach education resources, for example) is lies, BS or not of value, but that there is content that is all three. As such, it is important that coaches consume information critically to avoid hopping on the latest coaching bandwagon, while also demonstrating an openness to change and innovation. Simply, it is important to maintain enough scepticism while also being open enough to incorporate new ideas into practice.

Imagine if scientists or doctors simply relied on information they had seen on Twitter or heard from someone who was not appropriately qualified or professionally thorough; there would be uproar! Yet it is currently acceptable, indeed for some laudable, for sports coaches to implement coaching practices or use information they have sought from potentially illegitimate sources. Note that this increasing use of uncritical sources (something we would question) is in parallel to calls for greater recognition of, and professionalisation in, coaching (something we are passionately in favour of and working to facilitate). The cost of BS can thus be extremely detrimental (Luks, 2017), both directly to practice and indirectly to reputation, particularly when considering the amount which is out in the open (Nielson, 2015). Of course, we might all have our favourite authors; one whose suggestions strike genuine chords with our experience. This is surely qualitatively and quantitatively flawed, however, if we only ever use that one source, all the time and indeed are encouraged to by 
the source itself. Note also that the echo chamber effect we mentioned earlier means that small groups of like thinking disciples may just mutually but blindly support.

It would seem to us that, in the face of increasingly polarised and group promoted, "this is the answer" sources, sports coaches, educators and administrators are somewhat lacking in the required education and knowledge to face this ongoing epidemic. Therefore, we propose that coaches must learn to think like a scientist in an effort to detect (and hopefully choose to avoid) BS. Unfortunately, however, critical thinking is not a common feature of interactions in sport (indeed it is more often than not discouraged!) and cheerleading rather than criticality is the prevalent behaviour. Could learning to think like a scientist, to question what is presented in a logical manner, help kill off misconceptions, bad practice and ill-informed decision making in coaching? In turn, could this level of criticality provide confirmation for potentially good ideas?

\section{Thinking like a Scientist}

Carl Sagan, the noted philosopher, describes how easily we can all be fooled and then goes on to explain that scientists have been trained to cope with this reality with what he terms a "baloney detection kit" - essentially a toolkit for critical thinking, which consists of a set of skills and competencies (Catchings, 2015), and encompasses an individual's "ability to make decisions by analysing issues and evaluating options, recognising the existence of assumptions and the need to make inferences" (Walker \& Diaz, 2003, p. 64). Sagan (1995) offers a set of cognitive tools and techniques that uncover errors, flawed thinking, false assertions, preposterous claims, frauds, pseudoscience, and myths; simply, some very practical guidance on how to work out what is and is not "baloney" (or BS!). The baloney detection kit can be thought of as the tools of healthy scepticism that we can apply to everyday life. Sagan suggested that the kit should be brought out as a matter of course whenever new ideas are offered for consideration. Often these ideas are attractive because of 
who is proposing them (a figure of influence, authority, high stature, for example) or what they offer (identifying the next "sure thing" or silver bullet). We can think of a number of coaching initiatives that fit these descriptions! Tempting as it might be to adopt these ideas or practices on face-value, however, they should be examined for their truthfulness. If the new idea survives examination by the tools in the kit, it can be tentatively accepted, tested and then adopted.

Extending from Sagan's work, we propose a checklist (Table 1) to help coaches assess the veracity of a claim and sift through the noise of the coaching landscape. Each element of the checklist is outlined in more detail below.

There must be independent confirmation of the "facts." Coaches must be willing to ask for supporting evidence and not take all things at face value, even if the information is being offered by a valued source such as the National Governing Body or a respected coach. This type of thoughtful scepticism, and seeking evidence, should be encouraged as it stops coaches from simply adopting practices in good faith. Instead, this process encourages coaches to validate information, despite peer and social pressure to accept something, and should lead the coach to get a deeper understanding of the phenomenon under consideration. Look for attempts to offer a balanced presentation. Presentation of a position should acknowledge, and ideally list, the advantages and disadvantages of that position. Without these built in caveats (the law of it depends and on what!) you may well be in a BS environment. Indeed, high-performing, experienced coaches often surround themselves with a network of critical friends that offer constructive feedback and alternative opinions compared to novice coaches who are more likely to accept information from non-reliable sources (Nash, Sproule, \& Horton, 2017). Simply, avoid operating within insular networks that serve as an echo-chamber for certain viewpoints and instead surround yourself with divergent opinions that will challenge your understanding. 

both sides of the argument and weighing up the evidence allows you to arrive at a reasoned position for accepting or rejecting a particular stance. This type of debate should be (but rarely is) a feature of policy development and practice in coaching. It is (but very rarely) a positive feature of some blogs but far too infrequently.

The authorities can be wrong! Sagan tells us that "authorities" have made mistakes in the past and they will do so again in the future and suggests that in science "there are no authorities; at most, there are experts" (Purtill, 2017). Across the coaching landscape there are numerous examples of initiatives and approaches that have been pushed by figures of authority in NGBs or commercial coaching bodies. Based on Sagan's toolkit we urge coaches to look for the evidence and ask the question "why this way, and not another way?" often driven by political "neatness," what makes for a glossy intervention, extremely secondary sources such as popular books, or social media campaigns. A much better approach would be to have a broader and more open debate, with the different perspectives presented equally to coaches. Simply, if there is something to be explained, coaches should be encouraged to think of a range of solutions to a problem and test each of these solutions to ultimately alternatives and ways to allow the evidence and data decide. What survives, the that is often proffered.

Keep an open mind. Coaches should try not to get overly attached to an idea or way hypothesis that resists disproof in this Darwinian selection among "multiple working hypotheses," has a much better chance of being the right answer than the unitary approach 
Rather, they should ask themselves why they like the idea and then compare it with the alternatives to find which is the best fit for their specific context.

Measure things. Quantifying things takes the ambiguity and guesswork out of decision-making. Whenever possible, coaches should gather data to justify what they are doing, how they are doing it and, most importantly, why. Simply, coaches need to act like scientists by using their coaching context (e.g., the gym, pitch or pool) to test and evaluate the knowledge that they acquire (Weinberg \& Gould, 2019) and ensure it transfers to that context. This, rather than opinions and comments, offers a much better foundation for decision-making.

Occam's Razor. This convenient rule-of-thumb states that when you have two competing theories that make exactly the same predictions, the simpler one is the better. What does this mean? Coaching initiatives should be as simple as possible, but no simpler! "It depends". The concept of professional judgement and decision making (e.g., Collins \& Collins, 2015) stresses the conditional nature of coaching decisions and methodology. In simple terms, that more than one answer exists, that the "best" answer might vary from person to person or from time to time, and that a constant process of "test and adjust" is part of the way to optimise any coaching method. As an approach, this stresses the need for openness and adaptability in the coach and infers the necessity of presenting variety in solutions for educators.

\section{unregulated environment, coaches may be both susceptible and receptive to bullshit} (Pennycook et al., 2015). In this paper, we argue that an emphasis on critical and analytical thinking and a scepticism towards the source of information would be a positive step against susceptibility to BS. Instead, we stress the importance of interventions and cognitive 
strategies that help coaches guard against BS as an important element of coach education and a vital step in developing truly reflective practitioners. Indeed, keeping an open mind and understanding how we reject BS can make us more aware of our own (potential) BS (Pennycook et al., 2015).

As coaches, coach development practitioners, and academics ourselves, we are part of the coaching community and we offer these ideas in good faith. It is not our intention to police the integrity and legitimacy of coach education offerings or the dissemination of this content, but we do encourage constructive criticism as a feature of coach education in order to ensure there is a robust evidence base available to coaches. After all, and finishing like we started with a quote, "No matter how big the lie [or BS], repeat it often enough and the masses will regard it as the truth" (John F. Kennedy). BS is here to stay, and we need to take it seriously as an intellectual and analytical problem (Nielsen, 2005). We hope readers will take our comments with the courtesy, common-sense and criticality we intend.

\section{References}

Akram, W., \& Kumar, R. (2017). A study on positive and negative effects of social media on society. International Journal of Computer Sciences and Engineering, 5(10), $347-$ 354.

Bailey, R. P., Madigan, D. J., Cope, E., \& Nicholls, A. R. (2018). The prevalence of pseudoscientific ideas and neuromyths among sports coaches. Frontiers in Psychology, 9(641).

Baran, B. (2010). Facebook as a formal instructional environment. British Journal of Educational Technology, 41(6), E146-E149.

Barash, V. (2011). The Dynamics of Social Contagion [Unpublished doctoral thesis]. Cornell University. 
Catchings, G. (2015). A Practical model for critical thinking skill and leadership development (C/CTSLD). Management and Organizational Studies, 2(4), 42-53.

Christensen, L. T., Kärreman, D., \& Rasche, A. (2019). Bullshit and Organization Studies. Organization Studies, 40(10), 1587-1600.

Collins, D., \& Bailey, R. (2013). 'Scienciness' and the allure of second-hand strategy in talent development. International Journal of Sport Policy and Politics, 5(2), 183-191

Collins, L., \& Collins, D. (2015). Integration of professional judgement and decision-making in high-level adventure sports coaching practice. Journal of Sports Sciences, 33(6), $622-633$.

Crockett, Z., Dhar, R., \& Mayyasi, A. (2014). Everything is Bullshit. San Francisco, CA: Pricenomincs Inc.

Cole, T. (2001). Lying to the one you love: The use of deception in romantic relationships. Journal of Social and Personal Relationships, 18(1), 107-129.

Dabbagh, N., \& Kitsantas, A. (2012). Personal learning environments, social media, and selfregulated learning: A natural formula for connecting formal and informal learning. Internet and Higher Education, 15, 3-8.

Eyler, J., \& Giles Jr., D. E. (1999). Where's the learning in service learning? San Francisco, CA: Jossey-Bass.

Frankfurt, H.G. (2005). On Bullshit. Princeton, NJ: Princeton University Press.

Herr, P. M., Sherman, S. J., \& Fazio, R. H. (1983). On the consequences of priming: Assimilation and contrast effects. Journal of Experimental Social Psychology, 19(4), $323-340$.

Jamro, W. A., \& Shaikh, H. (2016). Exploring the Educational and Research Insights of Social Networks. International Journal of Computer Science and Information Security, 14(11), 626-631. 
Jones, J. (2016, April, 11). Carl Sagan Presents His "Baloney Detection Kit”: 8 Tools for Skeptical Thinking. Open Culture. http://www.openculture.com/2016/04/carl-saganpresents-his-baloney-detection-kit-8-tools-for-skeptical-thinking.html

Kelly, M. R. (2014). Bullshit as the absence of truthfulness. International Studies in Phenomenology and Philosophy, 2(2), 165-188.

Lindskold, S., \& Walters P., S. (1983). Categories for acceptability of lies. The Journal of Social Psychology, 120(1), 129-136.

Luks, F. (2017). The ugly, the bad, and the good: Bullshit as discourse, accursed share, and lubricant. Journal of Extreme Anthropology, 1(1), 85-90.

MacKenzie, A. \& Bhatt, I. (2020a). Opposing the power of lies, bullshit and fake news: The value of truth. Postdigital Science and Education, 2, 217-232.

MacKenzie, A. \& Bhatt, I. (2020b). Lies, bullshit and fake news: Some epistemological concerns. Postdigital Science and Education, 2, 9-13.

Martens, R. (1987). Science, knowledge, and sport psychology. The sport psychologist, 1(1), 29-55.

Matthews, P. (2015). Neighbourhood belonging, social class and social media - providing ladders to the cloud. Housing Studies, 30(1), 22-39.

Matthews, P. (2016). Social media, community development and social capital. Community Development Journal, 51(3), 419-435.

Nash, C., Sproule, J., \& Horton, P. (2017). Feedback for coaches: Who coaches the coach? International Journal of Sports Science and Coaching, 12(1), 92-102.

Nielson, R. K. (2015). Social Media and Bullshit. Social Media + Society, 1(1), 1-3.

Pennycook, G., Cheyne, J. A., Barr, N., Koehler, D. J., \& Fugelsang, J. A. (2015). On the reception and detection of pseudo-profound bullshit. Judgment and Decision Making, 10(6), 549-563. 
Pennycook, G., Fugelsang, J. A., \& Koehler, D. J. (2015). Everyday consequences of analytic thinking. Current Directions in Psychological Science, 24(6), 425-432.

Pennycook, G., \& Rand, D., G. (2019). Fighting misinformation on social media using crowdsourced judgments of news source quality. Proceedings of the National Academy of Sciences, 116(7), 2521-2526.

Petrocelli, J. (2018). Antecedents of bullshitting. Journal of Experimental Social Psychology, $76,249-258$.

Piggott, D. (2015). The Open Society and coach education: A philosophical agenda for policy reform and future sociological research. Physical Education and Sport Pedagogy, 20(3), 283-298.

Polgate, D. (2017). The effect of telling lies on belief in the truth. Europe's Journal of Psychology, 13(4), 633-644.

Purtill, C. (2017, April 14). Lie-proof your life with Carl Sagan's “balony detection” checklist. QUARTZ. https://qz.com/959775/carl-sagans-baloney-detection-kit-canhelp-you-spot-fake-news-and-weaponized-lies/

Sagan, C. (1995). The Demon-Haunted World: Science as a Candle in the Dark. New York, NY: Random House.

Smith, R. (2006). Peer review: A flawed process at the heart of science and journals. Journal of the Royal Society of Medicine, 99(4), 178-182.

Sperber, D. (2010). The guru effect. Review of Philosophy and Psychology, 1, 583-592.

Spicer, A. (2013). Shooting the shit: The role of bullshit in organisations. Management (France), 16(5), 653-666.

Stoszkowski, J., \& Collins, D. (2014). Communities of practice, social learning and networks: Exploiting the social side of coach development. Sport, Education and Society, 19(6), 773-788. 
Stoszkowski, J., \& Collins, D. (2016). Sources, topics and use of knowledge by coaches. Journal of Sports Sciences, 34(9), 794-802.

Sylvester, B. (2019, October 15). Fact check: Did Marcus Aurelius say 'everything we hear is an opinion, not a fact?' Check Your Fact. https://checkyourfact.com/2019/10/15/factcheck-marcus-aurelius-opinion-fact-perspective-truth-quote/

Tetlock, P. E., \& Gardner, D. (2015). Super-forecasting: The art and science of prediction. London, UK: Random House.

Trudel, P., Milestetd, M., \& Culver, D. M. (2019). What the empirical studies on sport coach education programs in higher education have to reveal: A review. International Sport Coaching Journal, 7(1), 61-73.

Walker, S., \& Diaz, L. G. (2003). Promoting critical thinking in the classroom. Athletic Therapy Today, 8(5), 64-65.

Walker, L. F., Thomas, R., \& Driska, A. P. (2018). Informal and nonformal learning for sport coaches: A systematic review. International Journal of Sports Science \& Coaching, 13(5), 694-707.

Weinberg, R. S., \& Gould, D. (2019). Foundations of Sport and Exercise Psychology. Champaign, IL: Human Kinetics.

Wingfield, B. (2017, September 26). Peer review: The 'least worst' barrier to bad science. Social Science Space. https://www.socialsciencespace.com/2017/09/peer-reviewleast-worst-barrier-bad-science/ 


\section{Table 1}

\section{Checklist to help coaches assess the veracity of a claim and sift through the noise of the coaching landscape}

\begin{tabular}{|c|c|c|}
\hline What & How & Why \\
\hline $\begin{array}{l}\text { There must be } \\
\text { independent confirmation } \\
\text { of the "facts." }\end{array}$ & $\begin{array}{l}\text { Be willing to ask for supporting evidence and } \\
\text { don't just take things at face value. }\end{array}$ & $\begin{array}{l}\text { This encourages you to validate information, despite potential peer } \\
\text { and social pressure to accept something, and should lead you to a } \\
\text { deeper understanding of the phenomenon under consideration. }\end{array}$ \\
\hline $\begin{array}{l}\text { Look for attempts to } \\
\text { offer a balanced } \\
\text { presentation. }\end{array}$ & $\begin{array}{l}\text { Any presentation of a position should } \\
\text { acknowledge, and ideally list, the advantages and } \\
\text { disadvantages of that position. }\end{array}$ & $\begin{array}{l}\text { Without these built in caveats (the law of it depends and on what!), } \\
\text { you may well be in a BS environment. }\end{array}$ \\
\hline Engage in debate. & $\begin{array}{l}\text { Sagan encourages "substantive debate" on the } \\
\text { evidence by knowledgeable proponents of all } \\
\text { points of view. }\end{array}$ & $\begin{array}{l}\text { Listening to both sides of an argument and weighing up the } \\
\text { evidence allows you to arrive at a reasoned position for accepting } \\
\text { or rejecting a particular stance. }\end{array}$ \\
\hline $\begin{array}{l}\text { The authorities can be } \\
\text { wrong! }\end{array}$ & $\begin{array}{l}\text { Look for the evidence and ask the question "why } \\
\text { this way, and not another way?" }\end{array}$ & $\begin{array}{l}\text { "Authorities" have made mistakes in the past and they will do so } \\
\text { again in the future. }\end{array}$ \\
\hline $\begin{array}{l}\text { Spin more than one } \\
\text { hypothesis. }\end{array}$ & $\begin{array}{l}\text { Think of a range of solutions to a problem and test } \\
\text { each of those solutions against alternatives. }\end{array}$ & $\begin{array}{l}\text { Solutions to coaching challenges are often driven by political } \\
\text { "neatness," what makes for a glossy intervention, secondary } \\
\text { sources such as popular books, or social media campaigns. }\end{array}$ \\
\hline Keep an open mind. & $\begin{array}{l}\text { Ask yourself why you like an idea then compare it } \\
\text { with the alternatives to find which is the best fit } \\
\text { for your specific context. }\end{array}$ & $\begin{array}{l}\text { It is important to not get overly attached to an idea or way of doing } \\
\text { something just because it is your idea, or it is something that you } \\
\text { have always done. }\end{array}$ \\
\hline Measure things. & $\begin{array}{l}\text { Whenever possible, gather data to justify what you } \\
\text { are doing, how you are doing it and, most } \\
\text { importantly, why. }\end{array}$ & $\begin{array}{l}\text { Quantifying things takes the ambiguity and guesswork out of } \\
\text { decision-making. This, rather than opinions and comments, offers } \\
\text { a much better foundation for decision-making. }\end{array}$ \\
\hline Occam’s Razor & $\begin{array}{l}\text { Coaching initiatives should be as simple as } \\
\text { possible, but no simpler! }\end{array}$ & $\begin{array}{l}\text { This rule-of-thumb states that when you have two competing } \\
\text { theories that make exactly the same predictions, the simpler one is } \\
\text { the better. }\end{array}$ \\
\hline "It depends" & $\begin{array}{l}\text { Coaches should consider and educators project the } \\
\text { conditional nature or context dependence of } \\
\text { coaching decisions. }\end{array}$ & $\begin{array}{l}\text { Statements on the most appropriate or optimum methodology are } \\
\text { inherently conditional, applying better to some contexts better than } \\
\text { others. Projecting this avoids the dogma of BS. }\end{array}$ \\
\hline
\end{tabular}

